\title{
An Insight into Embryonic Diapause in Animals
}

\author{
Mukesh Kumar Bharti ${ }^{1 *}$, Sriti Pandey ${ }^{2}$ and Ninan Jacob ${ }^{1}$ \\ ${ }^{1}$ Department of Veterinary Physiology, Rajiv Gandhi Institute of Veterinary Education and \\ Research, Kurumbapet, Puducherry, India \\ ${ }^{2}$ Animal Husbandry Department, District Hospital, Guna, Madhya Pradesh, India
}

*Corresponding author

\section{A B S T R A C T}

\begin{tabular}{|l|}
\hline Ke y w o r d s \\
$\begin{array}{l}\text { Embryonic } \\
\text { diapause, delayed } \\
\text { implantation, } \\
\text { blastocyst, } \\
\text { mammals }\end{array}$ \\
\hline Article Info \\
\hline $\begin{array}{l}\text { Accepted: } \\
\text { 20 August } 2019 \\
\text { Available Online: } \\
\text { 10 September } 2019\end{array}$
\end{tabular}

\section{Introduction}

Embryonic diapause is a temporary reversible cessation of embryonic development at the blastocyst stage. The development of the embryonic diapause concept is based on delayed implantation because of occurrence of post-implantation temporarily cessations of embryonic development (Fenelon and Renfree, 2018). During embryonic diapause there is a reversible cessation of embryo
Embryonic diapause is a phenomenon characterized by the temporary suspension of embryo development and delayed implantation in the uterus. It is an interesting reproductive strategy that has been frequently exploited across the animal kingdom. Mammalian embryonic diapause is categorized as obligate and facultative and broadly divided into three phases: entry into diapause, maintenance and termination of diapause. Obligate diapause occurs in every gestation of some species, while facultative diapause occurs in others, associated with metabolic stress, usually lactation. Embryonic diapause has been identified in over 100 animal species and the onset, maintenance and escape from diapause are regulated by cascades of environmental, hypophyseal, ovarian and uterine mechanisms that vary among species and between the obligate and facultative animal. However, the precise mechanisms by which the uterus exerts its influence on the embryo are still not clearly understood. Embryonic diapause is considered to be a permissive state for embryonic stem cell derivation, thus, its flexible occurrence in mammals opens new perspectives for reproductive and evolutionary biology. This review provides a deep insight about the prospects and possibilities of embryonic diapause in animal species. 
animal species for the success of embryonic diapause like delayed fertilization, delayed implantation, and delayed development (Burns, 1981). Embryonic diapause is widely reported in insects, fishes, birds and marsupials. Among placental mammals, it has been described in orders viz. Diprotodontia (Macropod, Kangaroos, Wombat), Rodentia (Rat, Mouse, Hamster), Insectivora (Moles, Shrews, Hedgehogs), Carnivora (Dog, Cat, Bear), Chiroptera (Old world fruit bats, Megabat, Flying Foxes), Edentata (Armadillo, Sloth, Anteater) and Artiodactyla (Cattle, Deer, Camel) but report of occurrence in Primates is less as this phenomenon was not investigated much in Primates.

Two forms of embryonic diapause found among animal species classified as the facultative and the obligate diapause (Mead, 1993). The facultative diapause is induced by physiological conditions like lactation and nutrition. In case of marsupials and rodents, this often takes place when the adult female is lactating in response to a previous reproductive event. While these animals are continuing nursing pups, newly fertilized oocytes enter into diapause and the blastocyst division pauses (Sherman, 1972). The second type of embryonic diapause is obligate diapause, which often occurs in roe deer (Capreolus capreolus) (Fenelon and Renfree, 2018) and in few other animals. Because of the occurrence of obligate diapause during every gestation period of the species, it is termed as seasonal diapause. Embryonic diapause is divided into three phases: onset, maintenance, and reactivation or termination of diapause.

The onset of embryonic diapause usually depends on environmental photoperiod, lactation and nutritional state. The maintenance period of diapause generally vary among species and even between individuals of the same species. Fischer (1931) reported that the delay of implantation in badgers lasts for 6 months, whereas in rats and mice it is only 4 to 10 days.

Findings of the several report suggests that embryonic diapause can be a basic reproductive phenomenon (Renfree, 2000). There is possibility to induce embryonic diapause in non diapausing mustelids, such as the ferret (Mustela furo), by influencing their endocrine secretion (Foresman and Mead, 1978).

Lactating rats are the most commonly used mammalian models for the occurrence of embryonic diapause as reported by Lataste, (1891). Artiodactyla, the roe deer (Bischoff, 1854 , c.f. Sempere, 1977) is the only species in which embryonic diapause was reported since 1854.

Later, Brinklow and Loudon, (1993) reported its occurrence in other species belonging to this suborder (Cervidae), such as the Pe're David's deer (Elaphurus davidianus). Embryonic diapause is inducible in the blastocyst from domestic sheep which belongs to the same suborder as the roe deer. Due to the difficulty of studying embryo development in wildlife the current knowledge about embryonic diapause in mammals is limited.

\section{Initial reports of Embryonic Diapause}

Bischoff (1854) was the first to scientifically report embryonic diapause in mammals i.e. in roe deer (c.f. Sempere, 1977)

Lataste (1891) showed lengthened gestation in female rodents suckling large litters (c.f. Psychoyos, 1992).

William Harvey observed differential states of embryonic development following examination of uterine contents of roe deer (Hunter, 1995). 


\section{Occurrence of Embryonic Diapause}

Biologists viz. embryologists, evolutionist, endocrinologists and animal scientists have been puzzled by the reversible arrest of embryo development which occurs in over 100 animal species across the animal kingdom, nematodes, insects, non-mammalian vertebrates and mammals.

\section{Types of Embryonic Diapause}

Embryonic diapause can occur as obligate or facultative diapause (Mead, 1993; Renfree and Shaw, 2000; Lopes et al., 2004). Obligate diapause characterizes each gestation of a species, while facultative diapause is related to some condition, usually lactational or metabolic stress which, when relieved, allows implantation to occur. Lactational diapause is common in rodent species that have a postpartum estrus and in marsupials where the ovarian cycle and inter-uterine embryo development occurs together. Some marsupial species display a combination of the two types of diapause, where lactational delay is further extended by seasonal photoperiodic signal (Renfree and Shaw, 2000).

\section{Stages of Embryonic Diapause}

Embryonic diapause can be divided into three phases

Entry into diapause

Maintenance of diapause

Reactivation (or termination) of diapause.

\section{Entry into Diapause}

Renfree (1981) reported that in Tammar wallabies (marsupials) mating occurs the day after the birth of offspring. The resulting zygote grows to be a blastocyst consisting of approximately 100 cells, and then the development is paused which signifies the beginning of embryonic diapause. Hormones released due to the young (in mothers pouch) suckling the mothers teat, halts the development of the blastocyst (lactational diapause).

\section{Maintenance of Diapause}

The mechanisms causing differing time period of embryonic diapause i.e. from suspension of blastocyst development to termination vary with species. In marsupials embryonic diapause lasts for 11 months of the year and it is the suckling stimulus that initially causes diapause. Renfree and Shaw, (2000) reported that the continued suckling of the neonate is one mechanism that is partially responsible for the maintenance of diapause.

Mead, (1981) reported that in mustelids (e.g. spotted skunk) diapause is maintained by uterine conditions that are insufficient for supporting a pregnancy, once ideal conditions are present diapause is terminated.

In the European badger, poor nutrition can lengthen the span of diapause (Lopes et al., 2004). These are all single factors affecting maintenance of diapause. However, Scientists believe that the presence of just one inhibitory factor is not enough to maintain diapause (Renfree et al., 1981).

\section{Reactivation (Termination) of Diapause}

Reactivation is the termination of embryonic diapause that allows blastocyst growth and development to resume. In marsupials, this generally occurs around the summer solstice in the southern hemisphere. Sadlier et al., (1977) reported that in marsupials a three hour decrease in photoperiod results in birth delay of 29-36 days hence, it can be inferred that reactivation is photo-periodically induced. Tyndale Biscoe et al., (1974) observed that hormone melatonin control the seasonal diapause. 


\section{Regulation of Embryonic Diapause}

\section{Maternal Control}

Maternal environment is the crucial factor to maintain diapause. Rodent blastocyst survive, but do not implant when transferred to the uterus of ovariectomized, progesterone treated adult females (Weitlauf and Greenwald, 1968) or the oviducts of intact, immature females (Papaioannou and Ebert, 1986). Chang, (1968) suggest that the uterus inhibits the renewal of embryonic development in obligate diapause. For this study they did transplant experiments where blastocyst from the ferret (a nondiapause species) was arrested in development when transferred to the mink uterus, while mink blastocyst reinitiated embryogenesis in the ferret uterus. Moreau et al., (1995) provides further evidence that the uterus maintains diapause where they co-cultured Mink embryos in diapause with member of same species uterine cell lines and found that embryo displayed the capacity for embryonic development in vitro.

\section{Pituitary Control}

The effect of prolactin on embryo implantation and diapause seems to be different in different group. Prolactin is the key factor essential for embryo implantation in mustelids carnivores. Murphy and Rajkumar (1985) in the mink and Mead (1993) in spotted skunk showed that circulating levels of prolactin increases some days prior to implantation in these species. Papke et al., (1980) in their study observed that treatment of mink in diapause with prolactin terminates diapause, while dopamine agonists (at doses that prevent prolactin secretion) prevent implantation. It was observed that in mink withdrawal of the dopamine agonist (Papke et al., 1980) or administration of dopamine antagonists (Murphy, 1983) terminates diapause. In contrast to mustelids carnivores,
Renfree and Shaw (2000) found that prolactin plays an inhibitory role in embryonic diapause of macropod marsupials. They found that while hypophysectomy terminates diapause, suckling-induced prolactin delay implantation. Long photoperiods block prolactin pulsatile secretion which prevents inhibition of implantation. Dey et al., (2004) observed that rodent facultative diapause is terminated by a short lived surge of estrogen from the ovary.

\section{Ovarian Factor}

Mead (1993) and Murphy et al., (1993) observed that during diapause there was a marked reduction in size as of corpus luteum occurred that results in low levels of progesterone. Douglas et al., (1998) found that in contrast to the pattern of terminal differentiation that characterizes corpus luteum development in most species, the mink corpus luteum retains its mitotic potential during the period of diapause. In response to the pituitary prolactin signal that terminates diapause, the corpus luteum is reactivated resulted in increased concentration of progesterone output (Murphy et al., 1993). Studies in the ferret (Foresman and Mead, 1978) and mink (Murphy et al., 1983) indicated that a luteal protein in combination with progesterone is required for successful implantation. Renfree and Shaw, (2000) observed that in marsupials (wallaby), the corpus luteum that develops during the estrous cycle can only be inactivated by lactational or seasonal prolactin secretion. Reactivation occurs when this inhibitory influence is removed. In case of rodents, the absence of an ovarian estrogen pulse maintains diapause, but the ovarian structures from which the steroid is released has not been identified.

\section{Uterine Factors}

The concept of uterine regulation of diapause in animal is demonstrated by the findings of 
Ptak et al., (2012) where they found that the sheep blastocyst induced to undergo developmental arrest if transferred to the uterus of pseudopregnant mice and when transplanted back to the uterus of the ewe, produce normal lambs. Another study in mouse by Paria et al., (1994) has been done to study the involvement of uterus in diapause. In this study they found that in the mouse reactivation of the uterus after diapause is regulated by ovarian steroid hormones and the induction of a favorable uterine environment is required for subsequent development of the blastocyst. However, Weitlauf (1974) found that the in vitro addition of steroid hormones directly to mouse embryos in diapause does not result in their reactivation.

It is said that numerous factors secreted by the uterus that are essential for the implantation process which are common to multiple species. An optimal uterine environment is essential for embryonic implantation and uterine secretions are key regulators of embryonic development. The mechanisms by which the uterus induces and maintains developmental arrest remain to be established. The pertinent question is whether diapause is due to the absence of uterine factor(s) necessary for development beyond the blastocyst, or whether the uterus actively maintains diapause by inhibition of development. There are several classes of proteins, adhesion factors, cytokines and growth factors secreted from uterine fluid includes LIF (leukemic inhibitory factor), COX2 (cyclooxygenase-2) and VEGF (vascular endothelial growth factors) and the receptors for these proteins were reported to be present in mink (Murphy 2012).

\section{Possibilities to Induce Embryonic Diapause in Large Animal Species}

Embryonic diapause is a fascinating biological mechanism for successful reproduction in animals. Its onset, maintenance and termination in mammals are under maternal control and this phenomenon is influences by lactation and environmental factors. Due to the absence of uterine and ovarian mitogens, reduction or cessation of mitotic activity in the embryo takes place which shows that mitogens is necessary for development of the embryo beyond the blastocyst stage. In case of mammalian embryos it has been seen that it can develop independently until the blastocyst stage and after that they recognize uterine signals necessary for their further development. In the absence of such signals by the uterus, the growth of embryos will stop or retard.

Thus embryonic diapause is an adaptation of the embryo to environmental constraints. Aitken (1975) opinioned that just like it occurs in the diapausing roe deer it is possible that blastocyst from sheep also grow slowly but continuously throughout the duration of diapause. On the other hand, sheep blastocyst might need more time to completely stop proliferation. Mead (1981) found it interesting that growth arrest in diapausing embryos in mustelids do not lead to death and even embryos which cannot implant due to exposing the female to constant darkness or following ovariectomy, are able to survive for long periods (300 days). It has been recently suggested that cell death is avoided during embryonic diapause as there is no risk of oxidative stress because opening of the mitochondrial permeability transition pore and release of cytochrome $\mathrm{C}$ do not occur (Hand and Manze, 2008). Lower cell death during embryonic diapause could be also due to DNA repairing activity (Surani and Fishel, 1981).

Chang (1968) suggested that it is possible to induce diapause in species where it does not normally occur for this experiment blastocyst from the ferret transplanted to the mink uterus and found that blastocyst cease development. 
In case of ferrets a pre-implantation delay can be induced by experimental manipulation of either pituitary (Murphy, 1979) or ovarian (Foresman and Mead, 1978) hormone.

Table.1

\begin{tabular}{|c|c|c|}
\hline Characteristics & Facultative Diapause & Obligate Diapause \\
\hline Distribution & Rodents, marsupials & $\begin{array}{l}\text { Mustelid, ursid and phocid carnivores, } \\
\text { roe deer, some bats and armadillos }\end{array}$ \\
\hline Present in & $\begin{array}{l}\text { Induced by environmental } \\
\text { conditions }\end{array}$ & Every gestation of a species \\
\hline $\begin{array}{l}\text { Developmental } \\
\text { status of blastocyst } \\
\text { in diapause }\end{array}$ & $\begin{array}{l}\text { Hatched in rodents; } \\
\text { Encapsulated in marsupials }\end{array}$ & $\begin{array}{l}\text { Hatched in roe deer and armadillo, } \\
\text { Encapsulated in carnivores }\end{array}$ \\
\hline $\begin{array}{l}\text { Mitotic activity in the } \\
\text { embryo in diapause }\end{array}$ & None & $\begin{array}{l}\text { Minor proliferation in some species } \\
\text { restricted to trophoblasts }\end{array}$ \\
\hline $\begin{array}{l}\text { Stimulus for entry } \\
\text { into diapause }\end{array}$ & $\begin{array}{l}\text { Lactation and metabolic } \\
\text { stress }\end{array}$ & Developmental stage in all gestations \\
\hline $\begin{array}{l}\text { Exogenous stimulus } \\
\text { for exit from } \\
\text { diapause }\end{array}$ & $\begin{array}{l}\text { Weaning (photoperiod in } \\
\text { some marsupials) }\end{array}$ & Photoperiod \\
\hline $\begin{array}{l}\text { Endogenous stimulus } \\
\text { for exit from } \\
\text { diapause }\end{array}$ & $\begin{array}{l}\text { Ovarian estrogen (rodents); } \\
\text { Prolactin withdrawal } \\
\text { (marsupials) }\end{array}$ & $\begin{array}{l}\text { Unknown ovarian factors, } \\
\text { Prolactin secretion }\end{array}$ \\
\hline
\end{tabular}

Tarin and Cano (1999) suggested that diapause or developmental delay can occur in human embryos based on the appearance of chorionic gonadotropin secretion. This suggests that many mammalian species might be capable of expressing diapause under appropriate conditions.

The causes for entry into diapause may be due to lack of maternal signaling (Psychoyos, 1973) or surgical removal of the ovaries which prevent the occurrence of the estradiol surge, necessary for uterine receptivity. A maternal trigger is necessary to release the blastocyst from diapause and for its progression through development. Thus, embryonic dormancy and inability to develop further are related to the absence of the uterine signal for implantation. The only report on ovine embryos that unable to implant was due to blastocyst which developed in the uterus of females lacking the endometrial glands (Gray et al., 2002). Though the embryos hatched and remained viable, they could not grow and elongate. It was found that the development of older embryos is retarded when placed in younger uterus in rat (Dickemann and Noyes, 1960), sheep (Lawson and Chahill, 1983), rabbit (Fisher, 1986), and horse (Wilsher et al., 2010).

Kaufmann et al., (1977) opined that embryonic diapause is considered to be a free state for embryonic stem cell derivation. In sheep, the inner cells mass can be isolated from diapausing embryos and cultured in conditions favoring the maintenance of pluripotency. However, in mouse, the presence of LIF (leukemic inhibitory factor) in culture is necessary to derive embryonic stem cells (ESC) from undifferentiated inner cell mass. 
Molecular signaling which trigger stem cells derivation and maintenance vary depending on the developmental stage of the embryo. In sheep, unlike in mouse, diapause entry occurs at more developmentally advanced blastocyst stage in which the epiblast is already formed.

It could be more advantageous to establish embryonic stem cells from diapausing sheep blastocyst using chemically defined activin containing culture medium.

It can be considered to be a starting point to verify the flexible occurrence of embryonic diapause in mammals which would open new perspectives for reproductive and evolutionary biology.

Embryonic diapause is a reproductive strategy that is used by more than 100 animal species. It is a mechanism to enhance reproductive fitness through which mammals can extend their gestational period and by doing so, time the birth of their young to a favorable season.

Two types of embryonic diapause occur in animal species as facultative and obligate. Prolactin and melatonin is important hormone which involve in this phenomenon. In case of facultative diapause the increase of prolactin suppresses the function of the corpus luteum, and there is a resultant deficiency of progesterone that induces the onset of embryonic diapause. The decrease of prolactin inhibits embryo development by inhibiting corpus luteum function in carnivores.

Several factors control embryonic diapause like maternal, uterine, ovarian and also photoperiod but the integrated information is still lacking as to how diapause is induced. Further research is needed to explore the mechanism responsible for embryonic diapause to protect endangered animals, and increase productivity in animal production industry.

\section{Future Prospect}

The embryo-uterine dialogue that first suspends development and then allows it to recommence, requires further exploration.

It would be valuable to confirm whether the uterus directly inhibits development during diapause, or whether the arrest in development is due to deprivation of factors necessary for further embryogenesis.

As we know little about the mechanisms of suspension of the cell cycle or about the strategy employed by the embryo to survive at the very low metabolic rate of diapause further studies are required in this aspect.

Rapidly evolving cell and molecular biology technology may provide the tools to answers these and other questions pertinent to diapause.

\section{References}

Aitken, R. J. 1975. Ultra structure of the blastocyst and endometrium of the roe deer (Capreolus capreolus) during delayed implantation. J. Anat. 119: 369384.

$\begin{array}{lllll}\text { Bischoff, } & \text { T. } & \text { L. } & \text { M. } & 1854 .\end{array}$ Entwickelungsgeschichte des Rehes. J. Ricker's Buchlandlung, Giessen.

Brinklow, B. R. and Loudon, A. S. 1993. Gestation periods in the Pe're David's deer (Elaphurus davidianus): evidence for embryonic diapause or delayed development. Reprod. Fert. Dev. 5: 567575.

Burns J. M. 1981. Aspects of endocrine control of delay phenomena in bats with special emphasis on delayed development. In: Flint APF, Renfree MB, Weir BJ (eds.), Embryonic diapause in mammals. J. Reprod. Fert. 61-66.

Chang, M. C. 1968. Reciprocal insemination and egg transfer between ferrets and mink. J. 
Exp. Zool. 168: 49-60.

Dey, S. K., Lim, H., Das, S. K., Reese, J., Paria, B. C., Daikoku, T. and Wang, H. 2004. Molecular cues to implantation. Endocr. Rev. 25: 341-373.

Dickmann, Z. and Noyes, R. W. 1960. The fate of ova transferred into the uterus of the rat. J. Reprod. Fert. 1: 197.

Douglas, D. A., Song, J. H., Moreau, G. M. and Murphy, B. D. 1998. Differentiation of the corpus luteum of the mink (Mustela vison): mitogenic and steroidogenic potential of luteal cells from embryonic diapause and postimplantation gestation. Biol. Reprod. 58: 1163-1169.

Fenelon, J. C., Renfree, M. B. 2018. The history of the discovery of embryonic diapause in mammals. Biol. Reprod. 99: 242-251.

Fischer, B. 1986. Effects of asynchrony on rabbit blastocyst development. J. Reprod. Fert. 86: 479-491.

Fischer E. 1931. Die Entwicklungsgeschichte des Dacheses und die Frage der Zeillingsbildung. Verb d Anat Ges erganzungsheft. 72s: 22-34.

Foresman, K. R. and Mead, R. A. 1978. Luteal control of nidation in the Ferret (Mustela putorius). Biol. Reprod. 18: 490-496.

Gray, C. A., Burghardt, R. C., Johnson, G. A., Bazer, F. W. and Spencer, T. E. 2002. Evidence that an absence of endometrial gland secretions in uterine gland knockout (UGKO) ewes compromises conceptus survival and elongation. Reproduction. 124: 289-300.

Hand, S. C. and Menze, M. A. 2008. Commentary: Mitochondria in energylimited states: mechanisms that blunt the signaling of cell death. J Exp Biol. 211: 1829-1840.

Hunter, R. H. F. 1995. Sex determination, differentiation and inter sexuality in placental mammals. Press syndicate of the university of Cambridge United Kingdom.

Kaufmann, M. H., Barton, S. C. and Surani, M. A. 1977. Normal post implantation development of mouse parthenogenetic embryos to the forelimb bud stage.
Nature. 265: 53-55.

Lataste, M. F. 1891. Des variations de duree' de la gestation chez les mammifie'reset de circonstances qui de'terminentces variations: the orie de la gestation retarde'e. C R Seances. Soc. Biol. Fil. 9: 21-31.

Lawson, R. A. S. and Cahill, L. P. 1983. Modification of the embryo maternal relationship in ewes by progesterone treatment early in the estrous cycle. J. Reprod. Fert. 61: 473-475.

Lopes, F. L., Desmarais, J. A. and Murphy, B. D. 2004. Embryonic diapause and its regulation. Reproduction. 128: 669-678.

Mead, R. A. 1981. Delayed implantation in mustelids with special emphasis on the spotted skunk.Embryonic Diapause inMammals. J. Reprod. Fert Suppl. 29: $11-24$.

Mead, R. A. 1993. Embryonic diapause in vertebrates. J. Exp. Zool. 266: 629-641.

Moreau, G. M., Arslan, A., Douglas, D. A., Song, J., Smith, L. C. and Murphy, B. D. 1995. Development of immortalized endometrial epithelial and stromal cell lines from the mink (Mustela vison) uterus and their effects on the survival in vitro of mink blastocyst in obligate diapause. Biol. Reprod. 53: 511-518.

Murphy, B. D. 1983. Precocious induction of luteal activation and termination of delayed implantation in mink with the dopamine antagonist pimozide. Biol. Reprod. 29: 658-662.

Murphy, B. D. 1979. The role of prolactin in implantation and luteal maintenance in the ferret. Biol. Reprod. 21: 517-521.

Murphy, B. D., Mead, R. A. and McKibbin, P. E. 1983. Luteal contribution to the termination of pre implantation delay in mink. Biol. Reprod. 28: 497-503.

Murphy, B. D., Rajkumar, K., Gonzalez, R. A. and Silversides, D. W. 1993. Control of luteal function in the mink (Mustela vison). J. Reprod. Fert Suppl. 47: 181188.

Murphy, B. D. and Rajkumar, K. 1985. Prolactin as a luteotrophin. Can. J. Physiol. 
Pharm. 63: 257-264.

Murphy, B. D. 2012. Embryonic diapause: advances in understanding the enigma of seasonal delayed implantation. Reprod. Domest. Anim. Suppl. 47 (6): 121-124.

Papaioannou, V. E. and Ebert, K. M. 1986. Development of fertilized embryos transferred to oviducts of immature mice. J. Reprod. Fert. 76: 603-608.

Papke, R. L., Concannon, P. W., Travis, H. F. and Hansel, W. 1980. Control of luteal function and implantation in the mink by prolactin. J. Anim. Sci. 50: 1102-1107.

Paria, B. C., Das, S. K., Mead, R. A. and Dey, S. K. 1994. Expression of epidermal growth factor receptor in the preimplantation uterus and blastocyst of the western spotted skunk. Biol. Reprod. 51: 205-213.

Psychoyos, A. 1973. Endocrine control of eggimplantation. Handbook of Physiology: Endocrinology. 2: 187-215.

Psychoyos, A. 1992. From lataste to the window of implantation: 100 years of fascinating discoveries. Contraception, fertilité, sexualité. 21: 333-338.

Ptak G. E. Tacconi E., Czernik, M., Toschi, P., Modlinski, J. A. and Loi, P. 2012. Embryonic diapause is conserved across mammals. PLoS. One. 7(3), e33027.

Renfree, M. B and Shaw, G. 2000. Diapause. Annu. Revi. Physiol. 62: 353-375.

Renfree, M. B. 1981. Embryonic diapause in marsupials. J. Reprod. Fert. Suppl. 29: 67-78.

Sadlier, R. M. F. and Tyndale-Biscoe, C. H. 1977. Photoperiod and the termination of embryonic diapause in the marsupial Macropuseugenii. Biol. Reprod. 16: 605-608.

Sempere, A. 1977. Plasma progesterone levels in the roe deer (Capreolus capreolus). J. Reprod. Fert. 50: 365-366.

Sherman M. I. and Barlow P. W. 1972. Deoxyribonucleic acid content in delayed mouse blastocyst. J. Reprod. Fertil. 29: 123-126.

Surani, M. A. H. and Fishel, S. B. 1981. Embryonic and uterine factors in delayed implantation in rodents. J. Reprod. Fert. 29: 159-172.

Tarin, J. J. and Cano, A. 1999. Do human concepti have the potential to enter into diapause? Hum. Reprod. 14: 2434-2436.

Tyndale-Biscoe, C. H., Hearn, J. P. and Renfree, M. B. 1974. Control of reproduction in macropod marsupials. J. Endocr. 63: 589-614.

Weitlauf, H. M and Greenwald, G. S. 1968. Survival of blastocyst in the uteri of ovariectomized mice. J. Reprod. Fert. 17: 515-520.

Weitlauf, H. M (1974). Metabolic changes in the blastocysts of mice and rats during delayed implantation. J Reprod Fert 39: 213-224.

Wilsher, S., Clutton-Brock, A. and Allen, W. R. 2010. Successful transfer of day 10 horse embryos: influence of donorrecipient asynchrony on embryo development. Reproduction. 139: 575585 .

\section{How to cite this article:}

Mukesh Kumar Bharti, Sriti Pandey and Ninan Jacob 2019. An Insight into Embryonic Diapause in Animals. Int.J.Curr.Microbiol.App.Sci. 8(09): 1841-1849.

doi: https://doi.org/10.20546/ijcmas.2019.809.213 